\title{
OSUL2013: Fostering Organizational Change through a Grassroots Planning Process
}

\section{Melanie Schlosser}

This paper provides background on planning and organizational culture change in libraries and describes a grassroots planning process taking place at the Ohio State University Libraries. Now in its third phase, the process aims to create a long-term plan for the organization while fostering a more collaborative, innovative culture.

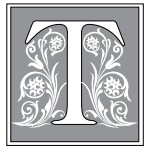

his paper shares the initial results of a grassroots planning process at the Ohio State University Libraries, along with information about strategic planning, grassroots efforts in libraries, and library organizational culture. The planning effort is presented as a response to the sweeping changes affecting the world of academic libraries, and its successes and failures are shared in the hope that other libraries will learn from our experiences and find inspiration in the resources we have gathered.

\section{The Times, They Are A-Changing Changes in the Library World}

I am sure it will surprise no one to hear that academic libraries are changing. Some of these changes are readily apparent to staff and users alike-like the growing prevalence of digital content. From 2003 to 2008, the percentage of ARL academic library collections composed of electronic resources increased from 30 percent to 53 percent. $^{1}$ This increasing abundance of digital content has revolutionized library research (particularly in the sciences) and library ownership models. The trend is widely appreciated by users, who have access to greater and greater amounts of content from an increasing range of devices, while also proving a cause for concern among those charged with the preservation of the scholarly record.

Another highly visible trend in academic libraries is the consolidation of library space on campus. The ability to research almost any topic from an office or a dorm room has lessened the demand for reading rooms, collections of print periodicals, and in-person reference service. As conscientious stewards of university resources, academic libraries have responded by redirecting funds and personnel. All 25 respondents to a survey of ARL Directors in April of 2009 reported current or planned library closures or size reductions. ${ }^{2}$ These reductions most often target science libraries, where online resources satisfy much of the demand.

Melanie Schlosser is Metadata Librarian and Assistant Professor at the Ohio State University Libraries; e-mail: Schlosser.40@osu.edu. All documents related to the OSUL2013 planning process can be accessed via OSU's Knowledge Bank, at https://kb.osu.edu/dspace/handle/1811/197. 
Other changes are less obvious. Before the advent of digital text and commercial services like Google Scholar, libraries served as a gatekeeper to the world of information. Users had to cross the threshold to access materials and, often, approach the reference desk to make sense of call numbers and subject headings. According to two large-scale surveys conducted in 2006, the value of the gatekeeper role of the academic library has decreased across all disciplines (although, again, particularly among scientists). In fact, while users "value the library, they perceive themselves to be decreasingly dependent on the library for their research and teaching and they anticipate that dependence to continue to decline in the future." ${ }^{3}$

Another change is invisible by definition. To better serve their users in a distributed digital environment, many libraries have worked to seamlessly integrate subscription resources into portals such as course management systems and commercial search engine results. A victim of their own success, the libraries themselves have become nearly invisible to users of those resources, and it is common to hear students (and even faculty) wonder why the library continues to pay for electronic resources when "you can get everything online." The cringing these comments elicit in library staff is an implicit recognition that "although librarians may still be providing significant value to their constituency, the value of their brand is decreasing." 4

\section{Change Closer to Home}

The Ohio State University (OSU) Libraries are not immune to the changes sweeping the library world. Composed of the University Libraries (OSUL), the Michael E. Moritz Law Library, the Prior Health Sciences Library, and the libraries at five regional campuses, the Libraries employ 435 faculty and staff (FTE), hold 5.8 million volumes, and receive 35,000 serial titles. ${ }^{5}$ The total number of people employed by the libraries has decreased slightly in recent years, but it has been accompanied by a tendency, common in the modern library world, toward a higher percentage of high-level and professional staff. OSUL has also joined its peer libraries in closing subject libraries with dwindling usage-most recently the journalism and business libraries - and cutting business hours in others.

Accompanying the changing staffing patterns and geography of the libraries are a leadership transition and a major renovation project. The previous director of OSUL left OSU in the summer of 2009 to become the first head of the libraries at the new KAUST University in Saudi Arabia. The new director began her tenure in January of 2010, and the libraries are watching eagerly to see what direction the new leadership will take.

The William Oxley Thompson Memorial Library, situated on the Oval at the heart of campus, is the most visible element of OSU's library system. In 2006 the Thompson Library was closed and library functions moved to a temporary facility on the edge of campus, beginning a three-year, \$108 million renovation. The project's aims were to modernize the building's infrastructure, restore the beauty of the original 1913 structure, and create a learning environment with a variety of individual and group study spaces. ${ }^{6}$ The project was exciting, not only because of the spectacular new building but also because of the incredible support and commitment demonstrated by the university at a time when state and university budgets are increasingly straitened and bricks-andmortar libraries are often undervalued.

These changes have not been without controversy. The closing of subject libraries and cutting of hours, although supported by usage data and budget projections, have ruffled feathers on campus. A weeding of the print collection necessitated by space constraints has produced a similar reaction. Even the Thompson Library's reopening in August 2009, while widely celebrated, has sparked complaints due to its smaller print collection. 


\section{More Change Coming}

Difficult though closing branches and making more efficient use of staff may be, there is a growing sense at OSU and in the library world that more change is coming, with or without our help. "Unless libraries take action," says the introduction to "No Brief Candle," a series of essays created from a Council on Libraries and Information Resources (CLIR) symposium, "they risk being left with responsibility for low-margin services that no one else (including the commercial world) wants to provide." ${ }^{77}$ Consensus has yet to emerge on what kind of action is necessary, but recent reports suggest a number of possibilities, including building new relationships with allies and users; $;$ identifying traditional roles that are no longer needed and potential roles that are; ${ }^{9}$ a focus on advocating for preservation and setting standards for quality control; ${ }^{10}$ and radically reconfiguring the library organization. ${ }^{11}$ Heightened collaboration is also a common suggestion, as is the need to align ourselves with trends in education and scholarly communication.

The lack of agreement on how to proceed is not the only barrier to change in libraries. There are two other powerful forces at work-budget and culture. Library budgets have failed to keep pace with increases in the cost of scholarly publications, and many libraries struggle simply to maintain current levels of service and collection building. In such an environment, it can be difficult to divert funds toward new services and cuttingedge technologies, no matter how crucial they may be. This financial scarcity "will tend to choke needed investments in emerging services addressing new user needs and new kinds of content." ${ }^{12}$ Even when resources can be found for such initiatives, staff may not embrace the necessary organizational changes. Libraries are not known as incubators of innovation and agile development-a situation that can be worsened significantly by a feeling of impending, uncontrollable change. "As uncertainty about the future persists, library staff may tend to cling to the familiar, resisting new approaches to the way they work."13

So if we cannot rely on an abundance of resources or a culture of innovation to carve a successful path for academic libraries in the 21st century, what will get us moving in the right direction?

\section{Planning for Change}

"There are a number of possible futures for the academic library, and strategic thought and change is needed to ensure that we move into a world in which the library continues to play an important role in the intellectual life of the campus."14

Planning is not a new concept in libraries. It is most commonly found in the form of strategic planning. Strategic planning is an approach to long-range planning that recognizes the importance of focusing on the relationships between an organization and its environment and stakeholders. It uses such tools as environment scans and SWOT (strengths, weaknesses, opportunities, and threats) analyses to identify opportunities and avoid predictable pitfalls. ${ }^{15}$ There are any number of sources for those deciding whether to create a strategic plan. Aamot, ${ }^{16}$ Anderson, ${ }^{17}$ Balasubramanian, ${ }^{18}$ Bednarz, ${ }^{19}$ and Butler ${ }^{20}$ all offer reasons for strategic planning in libraries. Brown ${ }^{21}$ offers both positive and negative aspects of the technique, and $\mathrm{Linn}^{22}$ argues against it as a good use of scarce library resources. Dougherty, ${ }^{23}$ Pacios, ${ }^{24}$ and Riggs ${ }^{25}$ offer guidance on choosing between strategic planning and other techniques, including long-range planning, total quality management, and reengineering. Nelson, ${ }^{26}$ Matthews, ${ }^{27}$ and Bryson ${ }^{28}$ all offer comprehensive guides to strategic planning in libraries. Others address it from the vantage of particular types of libraries, such as academic ${ }^{29}$ or school libraries. ${ }^{30}$ Others offer guidance on navigating the trickier aspects of planning in an environment with multiple stakeholders, ${ }^{31}$ an existing organizational culture, ${ }^{32}$ and complex organizational politics. ${ }^{33}$ Finally, while most of the literature on strategic planning deals 
with the process of creating a plan, there is guidance for those working to implement or evaluate an existing plan. ${ }^{34}$ For those seeking examples of strategic planning efforts in other organizations, a number of libraries have published accounts of their planning processes, including the Illinois State Library, ${ }^{35}$ NIST Research Library, ${ }^{36}$ the University of Southern California, ${ }^{37}$ Marquette Libraries, ${ }^{38}$ the Knowledge Integration Resources group at BristolMyers Squibb, ${ }^{39}$ public libraries in Sedona, Arizona, ${ }^{40}$ Indiana University Libraries, ${ }^{41}$ and Brown University. ${ }^{42}$ The Ohio State University as a whole is involved in a strategic planning effort that began with individual plans by academic units and has begun to impact the libraries, as will be discussed later in this paper.

There are a number of interesting planning initiatives taking place in libraries that fall outside the traditional strategic planning model. The University of Illinois at Urbana-Champaign's New Service Model process is one. Its aims are "priorities and directions for 'new service models' that would build on the Library's traditional strengths (including the depth of our collections and the quality of our services) to ensure that Illinois remains as much a leader in the provision of library services in the twenty-first century as it was throughout the twentieth. ${ }^{\prime 43}$ Building on input from faculty and staff, as well as the campus community, the New Service Model will take the form of a series of projects over the next few years. ${ }^{44}$ Space planning is a major focus of the New Service Model process; since 2006, it has overseen the closure of some subject libraries and the reorganization of others. As of March 2010, the process is still in full swing, with five teams working in areas including reference services, literatures and languages, and health information services.

The Berkeley New Directions Initiative is another innovative planning process. Its purpose is "to support an open process that will allow the Library to understand and adapt to the evolving information needs of our faculty and students." ${ }^{\prime 5}$ The "openness" of the process seems to be key, as evidenced by the objectives of the Coordinating Committee in the first phase:

"1. Provide opportunities for staff to learn about and reflect on the shifting Library environment, and future needs and services.

2. Engage the expertise of our staff, through multiple opportunities, to develop possibilities for new and enhanced Library services, or new ways existing service can be provided.

3. Implement our new directions developed by staff." 46

Following a series of town hall meetings and retreats, the Committee produced a "starting points" document that lists 165 potential goals in 21 areas (everything from technology to professional development to marketing). The library's administration then endorsed twenty-six of them, each of which is assigned to a member of the administration for implementation. The project's Web site states: "The first phase of New Directions is over and we are now entering the implementation phase. A new website will be up soon with news and documents for what's happening next!" However, no new information has been posted on the Web site or the blog since May of 2008 , and project leaders did not reply to requests for updates on its current status.

Transforming Texas Libraries is a similar process sponsored by the Texas Library Association (TLA) and the Texas Library and Archives Commission. Transforming Texas Libraries is "a statewide grassroots visioning process created to help guide Texas libraries over the coming years." ${ }^{\prime 7}$ Like Berkeley's process, the one in Texas is heavily reliant on participation at the grassroots. It is statewide in scope and includes a wide variety of libraries, as well as patrons and other stakeholders. Its focus is concrete phenomena affecting libraries and patrons, such as services, partnerships, marketing, and library organizational structure. It began with a statewide summit in fall of 2007 and continued with discussions at TLA events in 2008. Since 
then, according to its chair, Julie Todaro, implementation of its core ideas has been at the individual institution level and has included such successes as a redesign of service points in the Austin Public Library system and a reorganization of the TLA that includes more opportunities for digital member participation.

\section{We Decide to Change with Them OSUL2013 and Library Culture}

In early 2008, witnessing many of the same trends that inspired Berkeley and Illinois, the OSUL Executive Committee (a decision-making body consisting of the Director, the Assistant Directors, and staff officers) decided the time was right for a participatory planning process. Although librarians at OSUL have faculty status and faculty governance principles do apply in some areas, the decision-making process in the organization is largely top-down. This is a common phenomenon in academic libraries where the desire for shared governance is balanced by the need for quick decision-making and the inherent difficulty of managing a large, complex organization. Without existing structures for broad faculty and staff participation, it was necessary to begin an entirely new process for involving the grassroots in planning. The prospect was met with some skepticism, but also with a great deal of excitement, particularly among staff, who have fewer opportunities than faculty to participate in governance.

To begin the process, Maureen Sullivan, an organization development consultant specializing in libraries and other information organizations, was brought in to facilitate a full-day workshop attended by thirty-five faculty and staff, pulled from a larger group of volunteers. The staff involved consisted of both Classified Civil Service (CCS) and Administrative and Professional (A\&P) staff. After setting the gears in motion, the Executive Committee stepped back and allowed the process to be created and guided by the grassroots. The result was OSUL2013.
OSUL2013 is, ostensibly, a planning process. It is based on a shared vision of the future and moved forward by planning and projects. At its heart, though, its focus is not services, or technology, or library spaces-its focus is culture. The faculty and staff involved in the initial steps were quick to recognize the cultural barriers to change at OSUL and to identify culture as a crucial element in organizational success. Libraries as a whole have developed a distinct organizational culture over the years. As a service organization, the academic library is focused primarily on meeting the needs of students and faculty. "Therefore," writes Kaarst-Brown, "exploration of new services and evolution of current services are limited by the library's responsibility to the community," and potential innovations can face pushback by recalcitrant faculty. ${ }^{48}$

There is a wealth of information about the culture of libraries. The study of organizational cultures originated in the business world, but it has been applied to libraries by a number of writers. Malinconi$\mathrm{CO}^{49}$ and Shaughnessey ${ }^{50}$ were pioneers in introducing the concept to librarians, and they have been followed more recently by Kaarst-Brown, ${ }^{51}$ Schachter, ${ }^{52}$ Martin, ${ }^{53}$ and Selberg. ${ }^{54}$ Others have applied the study of organizational culture to specific aspects of librarianship. Jensen ${ }^{55}$ compares the cultures of libraries and publishers. McDonald ${ }^{56}$ studies the intersection between the culture of libraries and the values of the millennial generation. Budd ${ }^{57}$ looks at the culture of the research university and its impact on academic libraries. Casey ${ }^{58}$ suggests that libraries frequently nurture a "culture of no" and a "culture of perfection" that act as a barrier to change and innovation. Oud ${ }^{59}$ explores the role of organizational culture in the experiences of newly hired academic librarians. Many of these authors suggest that a change in library culture is needed, and a few have specific models in mind. Gluibizzi ${ }^{60}$ writes about the desirability of creating a "salon culture" in libraries that is "focused on people, cultural production, and the interaction between librarians and the public as 
a form of conversation." Singh ${ }^{61}$ suggests that what is needed is a "marketing culture," while Sheng ${ }^{62}$ explores the possibility of creating a "Knowledge Innovation Culture." Lombardo ${ }^{63}$ draws on the study of learning organizations in proposing a "learning culture," and there has been much discussion of the need for a "culture of innovation" in libraries. ${ }^{64}$ The University of Saskatchewan Libraries, ${ }^{65}$ Harvard College Library, ${ }^{66}$ and the University of California at Berkeley Libraries ${ }^{67}$ have all published accounts of their attempts to mold their organizational culture. Finally, Sutton $^{68}$ and Linn ${ }^{69}$ discuss the importance of organizational culture in planning, as well as the need to understand and work with the existing culture in major planning endeavors.

The potential targets of cultural change at OSUL are many and varied. Casey's description of a "culture of no" would strike a chord with many in the libraries, as potential innovations are often faced with an avalanche of administrative and financial obstacles. Another cultural barrier to progress is the class system that has formed around the three levels of staff: faculty librarians, A\&P staff, and CCS staff. Each category brings strengths to the organization. Many of the civil service staff are not only skilled at their jobs but carry a large share of institutional memory. A\&P staff bring flexibility and a professional outlook. Faculty librarians improve the libraries' services through direct involvement in the scholarly process and act as liaisons to other faculty at OSU. With these strengths, however, has come the tendency for each group to develop its own distinct organizational culture. Unfortunately, those cultures often contain elements of distrust or resentment toward the others, which severely hamper efforts at cooperation. Staff often do not feel empowered to contribute their skills to collaborative projects or to pool their knowledge with faculty and administration in assessment and planning.

Another cultural challenge stems from the sheer size of the organization. The staff of the OSU Libraries is not large compared to peer institutions, but it is still sizable enough to provide a communications challenge. Add the university's culture of decentralization, and the result is a collection of nearly independent units with no more than a basic understanding of each other's roles. Since the organizational structure that has produced this effect is not likely to change significantly in the near future, it has become a cultural challenge-how to encourage a culture of communication and collaboration across administrative boundaries.

\section{OSUL2013 Principles}

The OSUL2013 process operates according to a number of principles: grassroots participation and direction; an organic, "phased" process; a positive orientation; and a focus on qualities, not processes.

Grassroots participation and direction: OSUL2013 relies on the support of the Executive Committee-mainly in the sense of allowing staff and faculty the time to participate-but it is motivated and directed entirely by the libraries' grassroots. Participating faculty and staff (both CCS and $\mathrm{A} \& \mathrm{P})$, who are also responsible for implementing projects and plans, make all decisions. Participation in the process is also entirely voluntary, as are the leadership roles. Each phase has a leadership team, which, while necessarily limited in size, is open to any interested faculty or staff member. Interested participants are also encouraged to take on leadership roles in project teams and small groups. For many staff members, these may be the first leadership positions they hold in the libraries.

Organic, "phased" process: In structure, OSUL2013 is set up as a series of sequential "phases." Each phase is a new opportunity for faculty and staff to get involved, and participants are expected to step in and out of the process as they have time and inclination. Perhaps somewhat unusually, the phases are "organic," in the sense that each one flows naturally from the work of the previous phase. While participants 
may engage in long-term planning, each phase is essentially self-directed and participants are expected to change direction and adapt the process as necessary.

While different from how the libraries normally do business, the principles above are not too far out of the ordinary for a grassroots planning process. It is the last two principles that make OSUL2013 fundamentally about changing the culture of the libraries, rather than simply planning.

Positive orientation: Maureen Sullivan began the initial planning workshop with an exercise: each person in the room shared one thing that they believe the libraries do well. That concept-starting with your successes and building on them - has been a fundamental principle of OSUL2013 since its inception. It is one reason the Appreciative Inquiry (AI) organizational change method has been a recurring topic throughout the process. AI is "the cooperative, coevolutionary search for the best in people, their organizations, and the world around them. It involves systematic discovery of what gives life to an organization or a community when it is most effective and most capable in economic, ecological, and human terms." ${ }^{\prime 70}$ $\mathrm{AI}$ is a complex and lengthy process, and it has not yet been fully implemented at OSUL, but its principles have informed the OSUL2013 effort from the beginning. It has been the attitude of the OSUL2013 leadership teams so far that they are not in the business of saying no. The most important thing for the process is that people participate. If the idea that brought them in is unusual or unworkable, it is the job of the leadership to provide support and guidance. When it has been necessary to choose which projects to implement, the guidelines for choosing have been carefully explained and a process set out for participants to revise and resubmit projects that were not initially chosen. It is one of the goals of OSUL2013 that staff and faculty with innovative ideas be able to bring them to the table without fear of being immediately shot down or criticized into giving up.
Qualities, not processes: The most unusual aspect of 2013, however, is that, from the very beginning, it has focused not on specific services and processes (such as circulation, reference, and technology), but on the qualities that we, as a library, want to exemplify. After the workshop, a small group of volunteers (the Team of Six) met to sift through the results and synthesize the themes that appeared. The ideas generated in the workshop dealt with familiar library functions, but they also touched on more nebulous concepts such as collaboration and innovation. The Team of Six was charged with proposing topics for further study by task forces, as well as the process by which they would operate. Rather than organize the task forces around functions that are already the provenance of existing committees and departments, the Team of Six identified five "qualities" that came to the fore during the planning workshop that we would like OSU Libraries to exemplify by 2013:

- Assessment: We want to nurture within OSUL a culture of assessment, where ideas and programs are judged on their merits, and decisions are made based on evidence.

- Collaboration: We want to empower individuals and units to collaborate with others, internal and external, to provide innovative services and make the best possible use of resources.

- Innovation: We want an organizational culture that encourages innovative thinking and agile development.

- Scholarly communication: We want to be not only a purchaser and preserver of published scholarly literature but also an active participant in the entire process and a leader in the changing scholarly communication landscape.

- Ubiquity: We want the materials and services of OSUL to be available, accessible, and apparent to our patrons at the point that they need them 


\section{OSUL2013 Phases}

\section{About the Task Forces Phase}

Five task forces-Assessment, Collaboration, Innovation, Scholarly Communication, and Ubiquity - were formed based on the recommendations of the Team of Six. Volunteers were divided into task forces by the Team of Six with the help of two members of the Executive Committee. Assignments were based largely on individual preference, although care was taken to ensure that each group had at least one member from a regional campus. Each task force consisted of a chair, a vice chair, three to five members, and a liaison from the Team of Six. The remaining Team of Six member acted as a coordinator for the process.

Each task force was charged with exploring its topic through the literature and other available resources and with producing a final report. The final reports consisted of a definition of the topic; a bibliography; a value statement that briefly stated how the topic could function as a "value" for the libraries and why it should be incorporated into our day-to-day work; and a blue sky vision, where the group disregarded all barriers to change and envisioned how the libraries could best embrace that value. In the blue sky section, the task force was free to reorganize people and resources and imagine an ideal scenario. The final section consisted of programming suggestions-more practical and short-term ideas for moving the libraries forward.

To accompany the final reports, the Team of Six created an executive summary. The summary contained background information about the task forces, a combined value statement and blue sky vision, and a list of "common threads." The common threads were themes that appeared repeatedly in the reports and included such elements as "the Libraries as a community hub," "empowered staff and focused leadership," and "training and education."

\section{About the Implementation Phase}

After the Executive Committee met with the Team of Six, they agreed to support the next phase of the process, which would begin to implement the ideas created by the task forces. The evaluations from the task forces suggested that, while participants enjoyed working in small groups, they appreciated the chance to come together occasionally for large group meetings. There were also a number of staff and faculty, some of whom participated in the task forces, who indicated that they were interested in participating in the next phase of the OSUL2013 process, but could not devote large amounts of time to it. For these reasons, and to allow the broadest possible participation, the Team of Six proposed that the Executive Committee charge two groups for the implementation phase: a small Implementation Team and a larger Implementation Community. The Team would function as the leadership for the process and would be responsible for managing projects based on the programming suggestions from the task force reports, creating a long-term plan for the libraries, meeting monthly with the Implementation Community, and proposing the next step in the process. The Community, which was open to all faculty and staff, was more fluid and informal. Its charge was to meet monthly with the Implementation Team, offer ideas and serve as a sounding board, and serve as a pool of volunteers for ad-hoc teams and projects.

Potential projects were identified in a brainstorming session at the first Community meeting and were evaluated using the following criteria: relevance to the goals of OSUL2013 and the task force reports, a "positive" focus (creating something new rather than tearing down an existing service), and the ability to be completed, or at least significantly advanced, during the nine-month implementation phase. Five pilot projects were selected:

- Adoption of Appreciative Inquiry process. Goal: taking concrete steps toward implementing Appreciative Inquiry (AI), an approach to change management. (Project currently in progress) 
- OSU Library Labs. Goal: to create a presence online where library services in early development stages can be promoted and customer feedback obtained. (Project complete)

- Online suggestion box. Goal: create an online suggestion box to listen and respond to customers in a timely manner. (Project complete)

- Organizational knowledge. Goal: improve communication within the libraries and provide a way for faculty and staff to find out what other departments and units do. (Project currently in progress)

- Innovation seed fund proposal. Goal: propose a program of small grants to OSUL faculty and staff with innovative ideas. (Project on hold)

The Team was also charged with creating a long-term plan for the libraries, using the ideas generated by the task forces. While the project teams were busy working, two members of the Team began framing the plan. A "pyramid" structure was soon devised, where the top layer was the most general and the bottom the most specific. To relate the plan to previous efforts and the broader work of the libraries, the libraries' Vision and Mission Statement were included as the top two layers of the pyramid. The next section consisted of high-level goals, distilled from the common threads section of the executive summary of the task force reports. They were:

\section{Library as Commons}

We will...

- Coordinate information resources, such as tools, expertise, and collections

- Support interdisciplinary teaching and research

- Provide physical and virtual space for collaboration and communication
Empowered Staff and Focused Leadership We will...

- Encourage staff and faculty to take initiative

- Continually develop competencies in priority areas

- Empower staff and faculty to assess and to innovate

\section{User-Centered Organization}

We will...

- Make decisions based on the needs of our current and potential users

- Rely on data, both quantitative and qualitative, in identifying those needs

\section{One Library System}

We will...

- Adopt shared goals

- Facilitate and encourage communication and collaboration between individuals and units

- Strive for transparency in decision-making

\section{Leadership in Scholarly Communications} We will...

- Lead innovative efforts in the creation, distribution, and management of scholarship in all formats

The pyramid structure and goals were presented to the full Implementation Team and the Community and also posted to the libraries' staff e-mail list. After some minor revisions, the goals were adopted as part of the plan. During two subsequent Community meetings, the participants broke into small groups to brainstorm objectives - more concrete plans and projects that would move the libraries toward accomplishing the goals. Faced with an extensive list of possible objectives, the Team struggled to choose a small number for each goal. It was eventually decided that, rather than select specific objectives to be accomplished in the coming year, the entire list would be included in an appendix to the plan. Recognizing that implementation of the plan would fall to 
everyone in the libraries, the Team wanted to offer as many ideas and options as possible. The objectives were not vetted for practicality or measurability. It was felt that an idea that seemed unrealistic or undesirable to one person could serve as a source of inspiration to another.

The long-term plan was presented to the libraries as part of the final report for the Implementation phase, along with project overviews and a proposal for the next step in the process.

\section{Continuing Efforts}

Following the implementation phase, a new group was formed with the following charge:

- Meet regularly (at least monthly) for discussion and consultation, learning and following appreciative principles

- $\quad$ Solicit and facilitate new and existing 2013 projects

- Assess the libraries' progress toward the goals outlined in the long-term plan, both within the group's activities, and in the libraries as a whole

- $\quad$ Propose the next phase of the 2013 process

The group, known as the 2013 Working Group, was formed in the midst of the leadership transition and during a time of diminishing resources, and members found it difficult to contribute enough time to fulfill its charge. As a result, the group decided to meet less frequently and to focus on sustaining projects that were already underway, while remaining poised to participate in upcoming organizational changes. The opportunity to do so arose with the formation of the strategic planning working group.

The work of the OSUL2013 process took on a vital new role with the recent announcement that the libraries have approximately six weeks to create a five-year strategic plan. The abbreviated timeline makes it impossible for the working group to incorporate the kinds of broad participation (staff and faculty discussions, environmental scans, and feedback on drafts) that such a process would ideally include. Fortunately, much of this work has already been completed by the participants of OSUL2013, and the strategic planning group will be able to draw upon their efforts. Five of its eleven members have participated in a 2013 phase or project, and all members are able to glean ideas and "feedback" from the reports created by the first two phases. In addition, the existing staff and faculty leadership groups that will participate in the strategic planning process are heavily invested in the 2013 process. A majority of the members of the faculty Planning and Policy committee are current or former 2013 participants, and the Staff Advisory Council has recently undergone a transformation of its charge and membership based on 2013 recommendations.

\section{Evaluating OSUL2013 \\ Similarity to Other Processes}

One question that inevitably surfaces is how many of the ideas and processes created by OSUL2013 are based in unique local circumstances and how many are reflections of larger library trends that would apply equally in other environments. It is worth looking at the library planning processes described earlier for similarities and key differences.

The University of Illinois' New Service Model process resembles OSUL2013 most closely in the process used. Its work is based on ideas gleaned from the grassroots and is implemented in small, agile project teams. Its focus, however, is much more concrete, centering around space planning and revising library services to meet current and future user needs. As a result, its successes are easily measured and its focus admirable.

The process for Berkeley's New Directions Initiative is based on a discovery phase, a processing phase, and an action phase. The discovery and processing phases are meant to incorporate broad grassroots participation (like OSUL2013), while the action phase consists mainly of 
administrative planning and implementation. Its 165 "starting points" also converge with and diverge from OSUL2013 in interesting ways. They are a mix of the concrete (faculty copyright training workshops) and the conceptual (encourage innovation and entrepreneurial thinking). Many of the concerns of 2013 are reflected in this substantial list.

Transforming Texas Libraries' "Six Elements for Transformation" - user focus, universal access, partnerships and collaboration, outreach, marketing, and accountability and preparation-overlap with 2013 principles and goals to a striking degree. Its implementation has also been diffuse and dependent on participant initiative. Its ongoing success is a model for other grassroots change processes.

Most of the elements of OSUL2013 can be found in other processes. This is a hopeful sign of convergence in the library world. At a time when no one seems to agree on how best to manage the coming change, it is encouraging that libraries are engaging their grassroots in planning and that those planning processes are coming to similar conclusions. With luck and dedication, these conclusions will lead to a variety of local implementations, and other organizations will be inspired by their successes and informed by their struggles in their own change processes.

\section{Participant Evaluations}

An evaluation was conducted at the end of each of the first two phases-once by paper evaluations passed out at a wrap-up meeting, and once by creating a page on the project wiki (located in the libraries' space on a larger university wiki) and inviting all participants to add comments and concerns. Evaluations by participants were largely positive. The task forces and the Implementation Community allowed participants the opportunity to work with people they might never have come in contact with otherwise - a fact that was noted with appreciation by many. In a similar vein, many participants enjoyed interacting with like-minded people in a process that is essentially positive and hopeful.

Most of the negative comments dealt with participants' anxiety about the future of the process. By the end of the implementation phase, 72 staff and faculty members had participated in OSUL2013 in some way-a 17 percent involvement rate. Many evaluations, however, stressed that greater participation would be necessary to keep the process going. Others expressed skepticism or cynicism about the libraries' ability to change and the Executive Committee's commitment to doing so. Some participants remembered past efforts to plan or to create innovative services that had foundered, indicating that, essentially, they would believe it when they saw it.

With regard to activities, participants were most enthusiastic about the brainstorming session and the project workas evidenced by their evaluations and by attendance patterns at Community meetings. While they appreciated the opportunity to learn from their task force work or their fellow group members, it was the ability to contribute something concrete to the process that was most highly valued. The near-instant gratification of a brainstorm or a short-term project seems to be an essential element in attracting participants and keeping them engaged.

\section{Measuring Success}

The focus on qualities rather than processes has made the OSUL2013 initiative unique and exciting. It has also made it difficult to gauge its success. Measuring progress toward the closing of a branch library is relatively easy; measuring progress toward ubiquity is a different prospect entirely. Three criteria seem especially relevant in determining whether or not OSUL2013 is a successful process. First is the fate of the process itself. It is probably inevitable that any grassroots effort will eventually feel the tension between an organic process and one that is tightly focused, between self-direction and effective leadership. As much as possible, OSUL2013 erred on the side of the organic and the self-directive. At times it has resulted in great excitement 
and initiative; at others, in disorganization and loss of momentum. It is not clear whether OSUL2013 will continue past the current phase. Participants still express a sense of investment and appreciate coming together with other like-minded staff and faculty, but the clearcut sense of purpose that characterized the beginning of the process has dwindled. The process may find new life in the changing face of the libraries, or it may dissolve to make way for new groups and new structures. Either way, it will have been a positive experience for those involved, and one hopes that it will continue to influence its participants as they shape the future of the organization.

The second criterion for judging success is whether or not the process has, indeed, succeeded in changing the culture of OSU Libraries. This is never an easy outcome to measure, but it is especially difficult in this case, as the university is undertaking its own university-wide process to create a high-performance culture. The libraries will begin participating in workshops in 2010, and any momentum developed by OSUL2013 to change our culture will fold into the larger initiative, while, one hopes, accelerating and guiding our transformation.

The last criterion is OSUL2013's influence on the libraries' forthcoming strategic plan. When OSUL2013 began, it was not clear whether the libraries would be asked to create a strategic plan. Our process was meant to guide the organization in the absence of a formal plan or to guide the group eventually charged with creating one. That second role has become more crucial than anyone could have anticipated. Those involved in OSUL2013 will likely consider their efforts a success if their ideas and values are reflected in the plan. Either way, the work of the planning group has been made easier because of them. They have also provided this group with the tools to create a plan that reflects the concerns of the libraries' community, giving it a legitimacy it might not otherwise have had.

Whether or not OSUL2013 is judged a success, however, we are glad to have undertaken it. Change is needed, and it will not happen without great effort and broad participation. It is time to build a new future for libraries, brick by brick, project by project, and person by person. We share the initial results of OSUL2013 in the hope that our experience will inspire and inform similar efforts elsewhere. We recognize that our process is not only a local effort but also part of an ongoing dialogue in the library world about the necessity of, and the best direction for, change. We look forward to hearing about changes taking place in other libraries and hope to have many more successes to share in the future.

\section{Notes}

1. Association of Research Libraries, ARL Statistics 2002-2003 (Washington, D.C: Association of Research Libraries, 2004); Association of Research Libraries, ARL Library Data Tables (Washington, D.C: Association of Research Libraries, 2009).

2. Anne Kenney, 2009. Informal survey of Association of Research Libraries Directors Discussion List on library closures (e-mail communication).

3. Russ Housewright and Roger Schonfeld, Ithaka's 2006 studies of key stakeholders in the digital transformation in higher education. Ithaka, 2008: 6. Available online at http://www.ithaka.org/ ithaka-s-r/research/Ithakas\%202006\%20Studies\%20of\%20Key\%20Stakeholders\%20in \%20the \%20 Digital\%20Transformation\%20in\%20Higher\%20Education.pdf.

4. Ibid., 30.

5. The Ohio State University Libraries, 2006. Ohio State University Libraries statistics 2005/2006. Available online at http://library.osu.edu/sites/libinfo/osulstats.php. [Accessed 10 August 2009].

6. The Ohio State University Libraries, 2009. Ohio State University Thompson Library renovation overview. Available online at http://library.osu.edu/locations/thompson-library/thompsonlibrary-renovation/project-overview/. [Accessed 10 August 2009]. 
7. Council on Library and Information Resources (CLIR), No Brief Candle: Reconceiving Research Libraries for the 21st Century (Washington, D.C.: Council on Library and Information Resources, 2008), 4 .

8. Charles B. Lowry, Prudence S. Adler, Karla Hahn, and Crit Stuart, Transformational Times: An Environmental Scan Prepared for the ARL Strategic Plan Review Task Force (Chicago: Association of Research Libraries, 2009).

9. Housewright and Schonfeld, Ithaka's 2006 Studies, 4.

10. CLIR, No Brief Candle, 4.

11. Lowry, Adler, Hahn, and Stuart, Transformational Times.

12. Ibid.

13. Ibid.

14. Housewright and Schonfeld, Ithaka's 2006 Studies, 33.

15. Richard M. Dougherty, "Planning for New Library Futures, “ Library Journal 127, no. 9 (May 15, 2002): 38.

16. Gordon Aamot, "Getting the Most Out of Strategic Planning," College \& Research Libraries News 68, no. 7 (2007): 418-26.

17. Lisa Anderson, "Strategic Planning for Your District or School Library," Indiana Libraries 27, no. 2 (July 2008): 78-79.

18. P. Balasubramanian, A. Rangaswamy, and S. Kanthimathi, "Strategic Planning: A Tool for Future Libraries," SRELS Journal of Information Management 43, no. 3 (Sept. 2006): 219-24.

19. John Bednarz Jr., "The Future of Planning," Library Administration \& Management 21, no. 2 (2007): 65-69.

20. Meredith Butler and Hiram Davis, "Strategic Planning as a Catalyst for Change in the 1990s," College and Research Libraries 53 (1992): 398.

21. Walter A. Brown and Barbara A. Blake Gonzalez, "Academic Libraries: Should Strategic Planning Be Renewed?" Technical Services Quarterly 24, no. 3 (Jan. 2007): 1-14.

22. Mott Linn, "Library Strategies: Organizational Culture: An Important Factor to Consider," Bottom Line: Managing Library Finances 21, no. 3 (Aug. 2008): 88-93.

23. Dougherty, "Planning for New Library Futures," 38.

24. Ana R. Pacios, "Strategic Plans and Long-Range Plans: Is There a Difference?" Library Management 25, no. 6-7 (2004): 259-69.

25. Donald E. Riggs, "Plan or Be Planned for: The Growing Significance of Strategic Planning," College \& Research Libraries 58, no. 5 (Sept. 1997): 400.

26. Sandra S. Nelson and Public Library Association, The New Planning for Results: A Streamlined Approach (Chicago: American Library Association, 2001).

27. Joseph R. Matthews, Strategic Planning and Management for Library Managers (Westport, Conn.: Libraries Unlimited, 2005).

28. John M. Bryson, Strategic Planning for Public and Nonprofit Organizations: A Guide to Strengthening and Sustaining Organizational Achievement, rev. ed. (San Francisco: Jossey-Bass Publishers, 1995).

29. Butler and Davis, "Strategic Planning as a Catalyst," 398; Sarah McNicol, "The Challenges of Strategic Planning in Academic Libraries," New Library World 106, no. 11 (Nov. 2005): 496-509.

30. Anderson, "Strategic Planning for Your District," 78-79.

31. Butler and Davis, "Strategic Planning as a Catalyst," 398.

32. Linn, "Library Strategies," 88-93.

33. Douglas G. Birdsall, "Strategic Planning in Academic Libraries: A Political Perspective," in Restructuring Academic Libraries: Organizational Development in the Wake of Technological Change (Chicago: Association of College and Research Libraries, 1997), 253-61. Available online at www. lita.org/ala/mgrps/divs/acrl/publications/booksmonographs/pil/pil49/birdsall.cfm. [Accessed 10 August 2009].

34. Juha Kettunen, "The Strategic Evaluation of Academic Libraries," Library Hi Tech 25, no. 3 (Aug. 2007): 409-21; McNicol, "The Challenges of Strategic Planning," 496-509.

35. "ISL strategic plan 2008-2011," Insight (2008): 3-4. Available online at http://www.cyberdriveillinois.com/publications/pdf_publications/insight_050608.pdf.

36. Nancy Allmang and Mylene Ouimette, Case Study: The NIST Research Library's Experience Using Focus Groups in Strategic Planning, vol. 21 (Chicago: American Library Association, 2007).

37. Shahla Bahavar and Judith A. Truelson, Strategic Planning for Reference in a Team Environment: The Preferred Futuring Model, vol. 47 (Chicago: American Library Association, 2008).

38. Susan H. Hopwood, "Long-Range Planning and Funding for Innovation," Computers in Libraries 19, no. 1 (Jan. 1999): 22.

39. Alvin L. Jacobson and JoAnne L. Sparks, "Creating Value: Building the Strategy-Focused Library," Information Outlook 5, no. 9 (Sept. 2001): 1.

40. David Keeber, "Process Analysis and Standardization: The Road to Strategic Planning 


\section{Fostering Organizational Change through a Grassroots Planning Process 165}

Success," Indiana Libraries 26, no. 4 (Dec. 2007): 37-42.

41. Jo McClamroch, Jacqueline J. Byrd, and Steven L. Sowell, "Strategic Planning," Journal of Academic Librarianship 27, no. 5 (Sept. 2001): 372.

42. Eric C. Shoaf, "Fifteen Months in the Planning Trenches: Strategically Positioning the Research Library for a New Century," Library Administration \& Management 15, no. 1 (Winter 2001): $4-13$.

43. University of Illinois at Urbana-Champaign University Library, "About the New Service Model Programs." Available online at www.library.illinois.edu/nsm/. [Accessed 10 August 2009].

44. New Service Models: Report to the Provost. (Urbana-Champaign: University of Illinois at Urbana-Champaign University Library, 2009).

45. University of California Berkeley Library, New Directions Web site. Available online at http://sunsite3.berkeley.edu/wikis/NDwiki/. [Accessed 10 August 2009].

46. University of California Berkeley Library. "Why the New Directions Initiative?" Available online at http://blogs.lib.berkeley.edu/newdirections.php/2007/09/24/why_the_new_development_initiative_and_w. [Accessed 10 August 2009].

47. "Transforming Texas Libraries." Available online at www.txla.org/temp/Transform.html. [Accessed 10 August 2009].

48. Michelle L. Kaarst-Brown, Scott Nicholson, Gisela M. Von Dran, and Jeffrey M. Stanton, "Organizational Cultures of Libraries as a Strategic Resource," Library Trends 53, no. 1 (2004): 33-53. 791.

49. S.M. Malinconico, “Managing Organizational Culture," Library Journal 109, no. 7 (1984):

50. T.W. Shaughnessy, "Organizational Culture in Libraries: Some Management Perspectives," Journal of Library Administration 9, no. 3 (1988): 5-10.

51. Kaarst-Brown, Nicholson, Von Dran, and Stanton, "Organizational Cultures of Libraries," 33-53.

52. Debbie Schachter, "The Importance of Understanding Organizational Culture," Information Outlook 9, no. 6 (June 2005): 18-19.

53. M.J. Martin, "'That's the Way We Do Things around Here': An Overview of Organizational Culture," Electronic Journal of Academic \& Special Librarianship 7, no. 1 (2006): 6.

54. Roxanne Selberg, “Organizational Culture Challenge: Don't Let Our Differences Keep Us Apart," Technicalities 29, no. 1 (2009): 1-14.

55. Michael Jensen, "Cultural Tenacity within Libraries and Publishers," Library Trends 57, no. 1 (2008): 24-29.

56. Robert H. McDonald and Chuck Thomas, "Disconnects between Library Culture and Millennial Generation Values," EDUCAUSE Quarterly 29, no. 4 (2006): 4-6.

57. John M. Budd, "The Organizational Culture of the Research University," Journal of Education for Library \& Information Science 37, no. 2 (Spring 1996): 154.

58. Michael Casey and Michael Stephens, "Turning 'No' into 'Yes'," Library Journal 132, no. 8 (2007): 27.

59. Joanne Oud, "Adjusting to the Workplace: Transitions Faced by New Academic Librarians," College E Research Libraries 69, no. 3 (May 2008): 252-66.

60. Amanda Gluibizzi, "Tickling the Ivory Tower: Toward a Salon Culture in Libraries," Art Documentation: Bulletin of the Art Libraries Society of North America 27, no. 1 (2008): 24-27.

61. Rajesh Singh, "Developing a Marketing Culture," Feliciter 53, no. 3 (June 2007): 145-47.

62. Xiaoping Sheng and Lin Sun, "Developing Knowledge Innovation Culture of Libraries," Library Management 28, no. 1-2 (2007): 36-52.

63. Cindy Lombardo, "Creating a Learning Culture in Your Library," Ohio Libraries 18, no. 3 (2005): 4-7.

64. Amos Lakos and Shelley Phipps, "Creating a Culture of Assessment: A Catalyst for Organizational Change," portal: Libraries $\mathcal{E}$ the Academy 4, no. 3 (July 2004): 345-61.

65. Carol Shepstone and Lyn Currie, "Transforming the Academic Library: Creating an Organizational Culture that Fosters Staff Success," Journal of Academic Librarianship 34, no. 4 (July 2008): 358-368.

66. S. Lee and M.E. Clack, "Continued Organizational Transformation: The Harvard College Library's Experience," Library Administration \& Management 10, no. 2 (Spring 1996): 98-104.

67. J.W. Barker, "Triggering Constructive Change by Managing Organizational Culture in an Academic Library," Library Acquisitions 19, no. 1 (1995): 9-19.

68. B. Sutton, "Long-Range Planning Public Libraries: Staff Perspectives," Library \& Information Science Research 15, no. 4 (Fall 1993): 299-323.

69. Linn, "Library Strategies," 88-93.

70. David L. Cooperrider and Diana Whitney, Appreciative Inquiry: A Positive Revolution in Change (San Francisco: Berrett-Koehler, 2005), 8. 


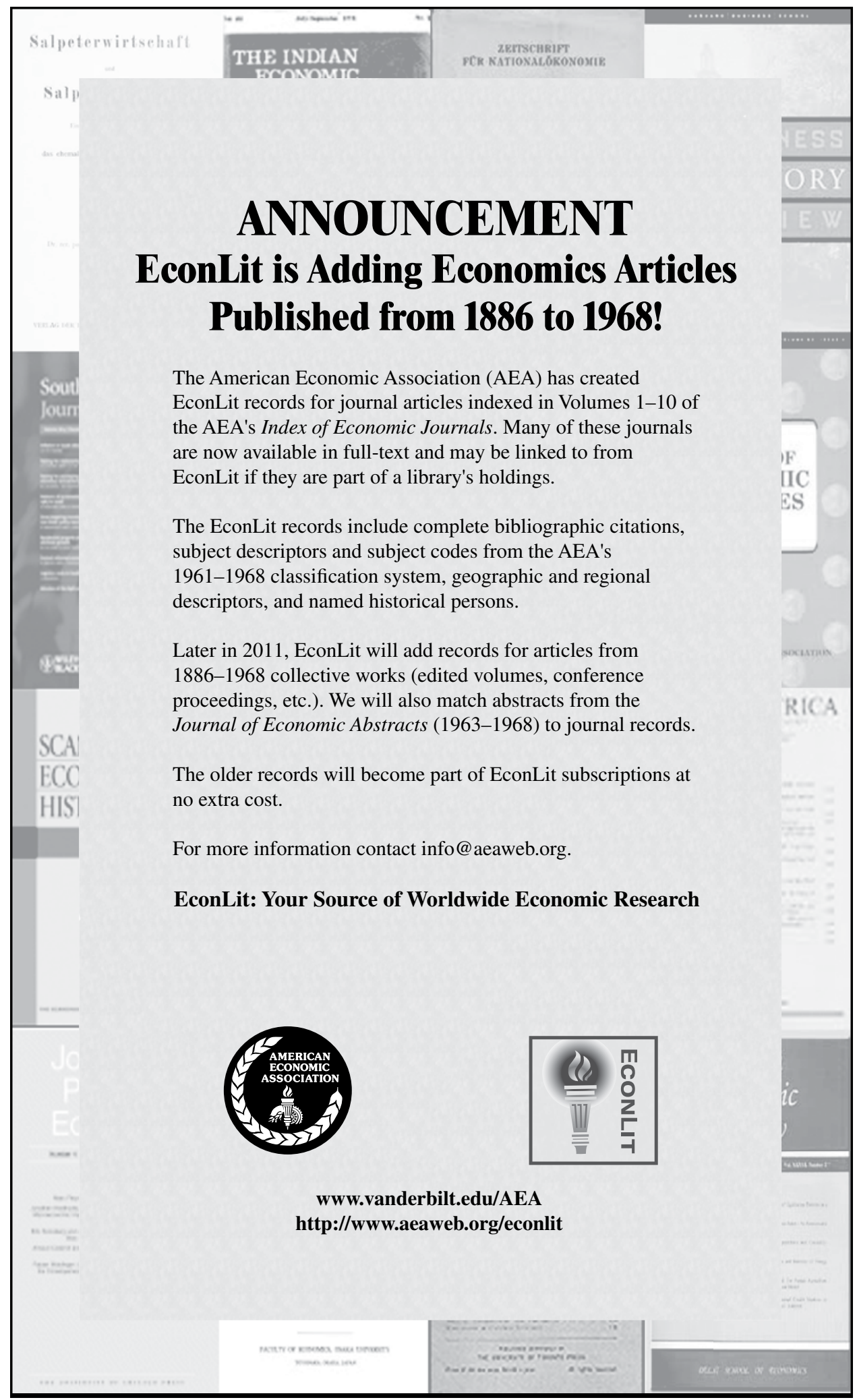

